\title{
Tumor location is a risk factor for lymph node metastasis in superficial Barrett's adenocarcinoma
}

\section{(ㄷ)(1) $\odot$}

\section{Authors}

Masayoshi Yamada ${ }^{1}$, Ichiro Oda ${ }^{1}$, Hirohito Tanaka' ${ }^{1}$, Seiichiro Abe ${ }^{1}$, Satoru Nonaka ${ }^{1}$, Haruhisa Suzuki ${ }^{1}$, Shigetaka Yoshinaga', Aya Kuchiba², Kazuo Koyanagi ${ }^{3}$, Hiroyasu Igaki ${ }^{3}$, Hirokazu Taniguchi ${ }^{4}$, Shigeki Sekine ${ }^{5}$, Yutaka Saito ${ }^{1}$, Yuji Tachimori ${ }^{3}$

\section{Institutions}

1 Endoscopy Division, National Cancer Center Hospital, Tokyo, Japan

2 Biostatistics Division, Center for Research Administration and Support, National Cancer Center, Tokyo Japan

3 Esophageal Surgery Division, National Cancer Center Hospital, Tokyo, Japan.

4 Division of Pathology and Clinical Laboratories, National Cancer Center Hospital, Tokyo, Japan

5 Division of Molecular Pathology, National Cancer Center Research Institute, Tokyo, Japan

submitted 20.10.2016

accepted after revision 26.6.2017

\author{
Bibliography \\ DOI https://doi.org/10.1055/s-0043-115388 | \\ Endoscopy International Open 2017; 05: E868-E874 \\ (c) Georg Thieme Verlag KG Stuttgart · New York \\ ISSN 2364-3722
}

Corresponding author

Masayoshi Yamada, M.D. Ph.D., 5-1-1, Tsukiji, Chuo-ku,

Tokyo, 104-0045, Japan

Fax: +81-3-3542-3815

masyamad@ncc.go.jp

\section{ABSTRACT}

Background and study aims Endoscopic treatment is indicated for superficial Barrett's adenocarcinoma (BA) with a negligible risk of lymph node metastasis (LNM). However, risk factors associated with LNM in superficial BA are still not well characterized. The aim of the current study was to clarify risk factors for LNM of superficial BA.

Patients and methods A retrospective study was conducted in 87 consecutive patients with BA that was resected at National Cancer Center Hospital, Tokyo, Japan between 1990 and 2013. We assessed tumor size, macroscopic type, histological type, tumor depth of invasion, lymphovascular invasion and tumor location to analyze factors associated with LNM. Tumor location was classified into following 2 groups according to Siewert classification: 1) BA of the esophagogastric junction (EGJ-BA) as those having their center within $1 \mathrm{~cm}$ proximal from the EG]; and 2) Esophageal-BA as those having their center at $1 \mathrm{~cm}$ or more proximal to the EGJ. EGJ was defined as distal end of the palisade vessels.

Results LNM was detected in $10(11 \%)$ patients. Univariable analysis revealed that tumor size, tumor depth of invasion, histological type of mixed differentiated and undifferentiated-type adenocarcinoma, lymphovascular invasion and tumor location of esophageal-BA were significantly associated with LNM. Multivariable analysis revealed that tumor location of esophageal-BA [odds ratio 7.8 (95\%Cl: $1.3-48.1$ ] ] was a potential risk factor for LNM.

Conclusions The current study demonstrated that tumor location is a potential risk factor for LNM in BA. Therefore, indications for endoscopic treatment of esophageal-BA and EGJ-BA could be different.

\section{Introduction}

In Japan, Barrett's esophagus (BE) is rare compared to incidence in Western countries [1,2]. However, the number of patients with BE could increase with the decline of Helicobacter pylori infection rates $[3,4]$.
Therapeutic endoscopy, including endoscopic mucosal resection (EMR), endoscopic submucosal dissection (ESD), radiofrequency ablation, photodynamic therapy and argon plasma coagulation, has been indicated for superficial Barrett's adenocarcinoma (BA) with a negligible risk of lymph node metastasis (LNM) [5,6]. Therapeutic endoscopy is effective and safe as a 
curative intent, and organ preservation is a great benefit for patients $[7,8]$.

Tumor invasion through muscularis mucosae into the submucosa, lymphovascular invasion and poor differentiation of tumor are known risk factors for LNM in BA [9-13]. However, risk factors were determined from surgical series in Western countries. Furthermore, risk factors according to location of the tumor based on Siewert classification are unknown [14]. Our hypothesis was that differences in wall structure between the esophagus and the EGJ may affect LNM of BA. The current study aimed to identify risk factors for LNM in superficial BA.

\section{Patients and methods}

Using a prospectively stored local histopathology database, the current study involved a total of 87 consecutive superficial BAs occurring among Japanese, which were resected at National Cancer Center Hospital, Tokyo, Japan, between 1990 and 2013. BA was defined as a tumor arising within or adjacent to an area of BE. BE was endoscopically defined as columnar-lined distal esophagus between the squamocolumnar junction and EGJ. EGJ was defined as distal end of the lower esophageal palisade vessels $[15,16]$. If the palisade vessels cannot be observed, EGJ was defined as upper ends of the gastric mucosal folds [17]. Maximum length of background BE was endoscopically measured between the estimated EGJ and proximal side of the squamocolumnar junction. Pathological report was also referred if the BE was long segment. This retrospective study was approved by the internal review board in our institution.

Of the cases, 50 were surgically resected between 1990 and 2013 and 37 cases were endoscopically resected between 1997 and 2011 with at least 3 years' follow-up observation. LNM of the surgically resected cases were evaluated in the resected specimens. LNM of the endoscopically resected cases was evaluated by annual computed tomography (CT) scans and/or endoscopic ultrasonography [18]. None of the patients received preoperative radiotherapy or chemotherapy. Of the 37 endoscopic resected cases, 2 underwent EMR and 35 underwent ESD.

Both surgically and endoscopically resected specimens were fixed in formalin spread out by pins. The surgically resected specimens were opened longitudinally and cut serially into 5$\mathrm{mm}$ thick sections. The endoscopically resected specimens were sectioned serially at 2-mm intervals. The slices were embedded in paraffin and all the sections were stained with hematoxylin and eosin (HE).

Tumor depth of invasion, histological type and lymphovascular invasion (LVI) were histologically evaluated. Tumor depth of invasion was subclassified as mucosa (pM), superficial submucosa (pSM superficial, $<500 \mu m$ into the SM) and deep SM (pSM deep, $\geq 500 \mu \mathrm{m}$ ). Histological type of the tumor was made by Japanese classification of gastric carcinoma and was classified as "differentiated-type" (tubular and papillary adenocarcinoma) and "mixed -type" (both differentiated- and undifferentiated-type within one lesion) [19]. Lymphovascular invasion was determined by HE staining, immunohistochemical a- nalysis using D2 - 40 monoclonal antibody for lymphatic invasion and/or Elastica van Gieson staining for vascular invasion.

Tumor size, macroscopic type and tumor location were evaluated based on the endoscopic findings. We used Japanese classification of esophageal cancer for expression of the macroscopic type [20]. Tumor location was classified into 2 groups in accordance with Siewert classification: 1) BA of the esophagogastric junction (EGJ-BA) as those having their center within 1 cm proximal to the EG]; and 2) esophageal-BA as those having their center at $1 \mathrm{~cm}$ or more proximal to the EG] [14] ( $\mathbf{F i g . 1 )}$.

\section{Statistical analysis}

A comparison of clinicopathological features, such as age, gender, tumor size, macroscopic type, histological type, depth of invasion, tumor location and present/absent of LVI, was made between LNM-positive and LNM-negative groups, and esophageal-BA and EGJ-BA groups.

For statistical analysis, exact test for categorical variables or Mann-Whitney $U$ test for continuous variable was used to compare patient characteristics between esophageal-BA and EGJ-BA. Univariable odds ratios (ORs) with $95 \%$ confidence intervals (Cls) were estimated. A logistic regression model was used to estimate ORs and $95 \% \mathrm{Cls}$ adjusted for potential confounders. The model included all variables with $P<0.05$ in the univariable analyses, which were tumor size, depth of invasion, histological type and lymphovascular invasion, and tumor location. We used receiver operating characteristic curve to find the best cutoff point of tumor size that could separate LNM-positive patients from LNM-negative patients; and our data suggested the cutoff of $26 \mathrm{~mm}$. Based on the result and the historical data [21], tumor size was divided into 2 categories with cutoff of $30 \mathrm{~mm}$. All $P$ values were 2 -sided and $P<0.05$ was considered significant.

\section{Results}

Patient characteristics are summarized in $>$ Table 1. Maximum length of background BE was $<1 \mathrm{~cm}$ in 34 cases $(39 \%)$, $\geq 1 /<2 \mathrm{~cm}$ in 23 cases (26\%), $\geq 2 /<3 \mathrm{~cm}$ in 13 cases (15\%) and $\geq 3 \mathrm{~cm}$ in 87 cases (20\%) [median $11 \mathrm{~mm}$ (range $2-120$ )]. Regarding macroscopic type, the present study included 3 cases of 0 -Ip (3\%), 12 0-Is (14\%), 22 0-Ila (25\%), 2 0-Ilb (2\%), 27 0-IIc (31\%) and 21 mixed type (24\%). The mixed type included 14 cases of 0 -IIa + Ilc (16\%), $1 \mathrm{Ilc}+\mathrm{Ilb}(1 \%), 1 \mathrm{Ip}+\mathrm{Ila}(1 \%), 2 \mathrm{Is}+\mathrm{Ila}$ (2\%), $1 \mathrm{Is}+\mathrm{Ilb}(1 \%), 1 \mathrm{Ip}+\mathrm{Ilc}(1 \%), 1 \mathrm{Is}+\mathrm{Ilc}(1 \%)$.

The 50 surgically resected cases [age $66(39-85)$, male/female: 46/4] included 8 and 42 cases of pM and pSM superficial/ deep, respectively. Mean tumor size was $17 \mathrm{~mm}$ (range 3-37). Among them, 9 cases were referred for additional surgery after non-curative ESD. In the remaining 41 cases resected by surgery only, the number of pM, pSM superficial and pSM deep were 8 , 8 , and 25 cases, respectively. In the 8 pSM superficial cases, 5 (63\%) were estimated pSM1, 2 (25\%) were pSM2, 1 (13\%) was pSM3. In contrast, in the 25 pSM deep cases, 11 (44\%) were estimated pSM2 and 14 (56\%) were pSM3, respectively. When compared pSM superficial/deep criteria in the current study and conventional criteria, most of the pSM superficial corre- 

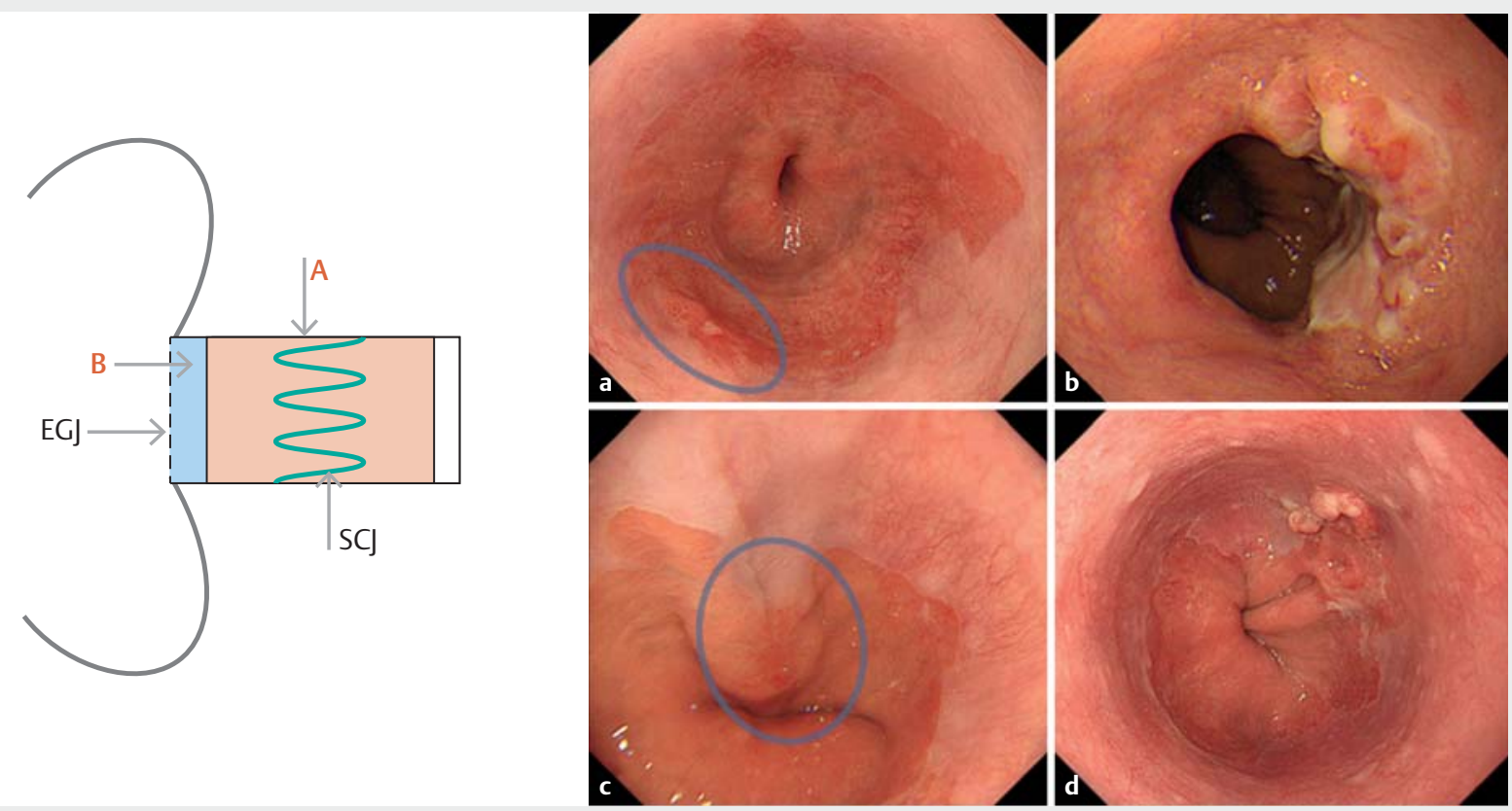

Fig. 1 Tumor location classified into 2 subtypes: A esophageal-BA (a, b) and B EGJ-BA (c, d)

sponded to SM1 and PSM deep corresponded to SM2 or 3 in the conventional criteria [22]. The 37 endoscopically resected cases [age 67 (41-88), male/female: 33/4] included 31 and 6 cases of pM and pSM superficial/deep, respectively. Mean tumor size was $28 \mathrm{~mm}$ (range $12-107$ ). No LNM or recurrences were discovered in the 37 endoscopically resected cases during a median follow-up period of 5.8 years (range $3.0 \sim 10.2$ ).

Compaing esophageal-BA and EGJ-BA, median tumor size was significantly larger, rate of mixed histological type and presence of LVI was significantly higher in esophageal-BA patients than in EGJ-BA patients ( $\triangleright$ Table 1 ).

Univariable analysis revealed that tumor size larger than $3 \mathrm{~cm}$, pSM deep invasion, histological type of mixed-type adenocarcinoma, LVI and tumor location of esophageal-BA were significantly more likely to be associated with the LNM-positive group than with the LNM-negative group ( $\triangleright$ Table 2). Multivariable analysis revealed that esophageal-BA in tumor location was a potential risk factor for LNM. In the 13 cases of pSM superficial, there were no patients with LNM. In the 35 cases of pSM deep, 5 of 10 patients with esophageal-BA ( $50 \%$ ) had LNM, while 3 of 25 patients with EGJ-BA (12\%) had LNM $(P=0.027)$.

Stratified proportion of LNM in the EGJ-BA is summarized in - Table 3. LNM was detected in 10 cases $(11 \%)$ that invaded into submucosal (SM) layer $1,000 \mu \mathrm{m}$ or more except for 2 cases with muscularis mucosae (MM) invasion ( $\$$ Table 4$)$. Only 1 case exhibited LNM from intramucosal BA with differentiated type adenocarcinoma without LVI that invaded into muscularis mucosae [23].

\section{Discussion}

Based on a systematic review, the proportion of LNM for intramucosal BA has been reported in 1.9\% (95\% confidence interval $1.2-2.7$ ) and LNM from intramucosal BA have been analyzed in a few studies [13, 24-26]. However, there are no data assessing risk of LNM based on tumor location. The current study demonstrated that tumor location within the esophagus was a potential risk factor for LNM. Possible explanations for the difference between esophageal-BA and EGJ-BA can be divided into 2 factors, the host side and the tumor side. As for the host side, high densities of lymphatic and vascular channels in the lamina propria mucosa (LPM) of the esophageal wall may offer a possible explanation. Yajin et al. studied D2 - 40 immunohistochemical staining of human lymphatic epithelium in the esophagus and found that LPM contained abundant longitudinally running lymphatic vessels [27]. Hahn et al. studied CD31 and D2-40 immunohistochemical staining for BE and found that superficial and deep LPM in BE each had significantly higher blood vessel and lymphatic vessel densities compared with the submucosa [28]. Because of this difference in wall structure, esophageal location was considered to be a potential risk factor for LNM in the current study.

Tumor size, tumor depth of invasion, histological type and LVI might affect LNM, although only tumor location was statistically significant by multivariable analysis [9]. According to results of the current study, the differences between EGJ-BA and esophageal-BA were larger size, higher proportion of mixed histological type, and LVI in esophageal-BA. There is a possibility that esophageal BA is already large and invasive on detection. An easily missed lesion or one that is rapidly growing is consid- 
- Table 1 Patient characteristics.

\begin{tabular}{|c|c|c|c|c|}
\hline & Esophageal-BA & EGJ-BA & Total & P value $^{1}$ \\
\hline & $n=17$ & $n=70$ & $n=87$ & \\
\hline Age $(y r)^{2}$ & $68(52-81)$ & $64(39-88)$ & $66(39-88)$ & 0.17 \\
\hline Gender (Male) & $15(88 \%)$ & $64(91 \%)$ & 79 (91 \%) & 0.64 \\
\hline Tumor size $(\mathrm{mm})^{2}$ & $41(5-107)$ & $22(3-60)$ & $23(3-107)$ & $<0.01$ \\
\hline \multicolumn{5}{|l|}{ Macroscopic type 3} \\
\hline - Flat & $6(35 \%)$ & $45(64 \%)$ & $51(59 \%)$ & 0.095 \\
\hline - Protruded and mixed & $11(65 \%)$ & $25(16 \%)$ & $36(41 \%)$ & \\
\hline \multicolumn{5}{|l|}{ Treatment strategy } \\
\hline - Endoscopy only & $4(24 \%)$ & $33(48 \%)$ & $37(43 \%)$ & 0.30 \\
\hline - Endoscopy+Surgery & 0 & $9(13 \%)$ & $9(10 \%)$ & \\
\hline - Surgery only & $13(76 \%)$ & $28(39 \%)$ & $41(47 \%)$ & \\
\hline \multicolumn{5}{|l|}{ Tumor depth of invasion } \\
\hline - pM & $4(24 \%)$ & $35(49 \%)$ & $39(45 \%)$ & 0.13 \\
\hline - pSM superficial & $3(18 \%)$ & $10(14 \%)$ & $13(15 \%)$ & \\
\hline - pSM deep & $10(59 \%)$ & $25(36 \%)$ & $35(40 \%)$ & \\
\hline \multicolumn{5}{|l|}{ Histological type } \\
\hline - Differentiated & $9(53 \%)$ & $55(79 \%)$ & $64(74 \%)$ & 0.028 \\
\hline - Mixed & $8(47 \%)$ & $15(21 \%)$ & $23(26 \%)$ & \\
\hline \multicolumn{5}{|l|}{ Lymphovascular invasion } \\
\hline - Absent & $8(47 \%)$ & $57(81 \%)$ & $65(75 \%)$ & $<0.01$ \\
\hline - Present & $9(53 \%)$ & $13(19 \%)$ & $22(25 \%)$ & \\
\hline LNM & $6(38 \%)$ & $4(6 \%)$ & $10(11 \%)$ & $<0.01$ \\
\hline \multicolumn{5}{|c|}{$\begin{array}{l}\text { EGJ, esophagogastric junction; BA, Barrett's adenocarcinoma; M/F, Male/Female; M, intramucosal carcinoma; SM, submucosal invasive cancer; superficial } \\
\text { <500 } \mu \mathrm{m} \text { invasion; deep, } \geq 500 \mu \mathrm{m} \text { invasion; Mixed, both differentiated- and undifferentiated-type within one lesion; LNM, lymph node metastasis. } \\
1 \text { Comparison between Esophageal-BA and EGJ-BA } \\
2 \text { Data were expressed as median and range. }\end{array}$} \\
\hline
\end{tabular}

ered as a possible characteristic of esophageal-BA that is mostly related to long-segment $B E$.

We tried to find patients with a low risk of LNM. In the EGJ-BA group, while the upper limit of the $95 \%$ confidence intervals was still high, none of the 34 cases with pM or 10 cases of pSM superficial without LVI had LNM (95\% confidence intervals, 0 10.2 and $0-28$, respectively). Therefore, these criteria may indicate patients who are good candidates for endoscopic treatment. Indeed, in our previous study about long-term clinical outcomes of 53 superficial adenocarcinomas of the EG] resected by ESD, superficial adenocarcinoma of the EGJ was well controlled by ESD when curative resection was achieved [29]. Given these differences in risk of LNM, we considered that indications for endoscopic treatment should be considered separately for esophageal-BA and EGJ-BA.

The esophageal-BA group had a higher risk of LNM even in the intramucosal BA. Based on the PSM deep subgroup, the proportion of LNM was significantly higher in the esophageal-
BA group than in the EGJ-BA group. However, because postoperative mortality for esophagectomy has been reported as $2 \%$ to $5 \%$ and can be associated with significant morbidity [11,30-32], some studies noted the possibility of endoscopic treatment for esophageal-BA with submucosal superficial invasion [33-36]. Particularly when submucosal superficial invasion is confined to the upper one-third of the submucosal layer, these patients might be considered low risk for LNM if the tumor is histological grade G1 or G2 and LVI is absent. Indeed, Manner et al. studied long-term clinical outcome of 72 patients with $\mathrm{pT} 1 \mathrm{~b}$ esophageal adenocarcinoma who underwent endoscopic resection with EUS follow-up or radical esophageal resection with $L N$ dissection. Because LNM was detected in only 1 patient (2\%) in the low-risk group during the median 5 year follow-up period, they concluded that endoscopic therapy may be chosen as an alternative to esophageal resection in low-risk patients [34]. Patients with esophageal-BA should re- 
- Table 2 Risk factors for lymph node metastasis.

\begin{tabular}{|c|c|c|c|c|c|}
\hline & \multirow{2}{*}{$\begin{array}{l}\text { Total } \\
\text { No. }\end{array}$} & \multicolumn{2}{|l|}{ LNM (\%) } & \multirow{2}{*}{$\begin{array}{l}\text { Univariable } \\
\text { OR (95\%Cl) }\end{array}$} & \multirow{2}{*}{$\begin{array}{l}\text { Multivariable } \\
\text { OR (95\%Cl) }\end{array}$} \\
\hline & & Positive & Negative & & \\
\hline & 87 & 10 & 77 & & \\
\hline \multicolumn{6}{|l|}{ Age (yrs) } \\
\hline.$<65$ & 39 & $3(30)$ & $36(47)$ & ref & \\
\hline . $\geq 65$ & 48 & $7(70)$ & $41(53)$ & $2.04(0.49-8.52)$ & \\
\hline \multicolumn{6}{|l|}{ Gender } \\
\hline - Male & 79 & $9(90)$ & $70(91)$ & ref & \\
\hline - Female & 8 & $1(10)$ & $7(9)$ & $1.11(0.12-10.1)$ & \\
\hline \multicolumn{6}{|l|}{ Tumor size } \\
\hline - $<3 \mathrm{~cm}$ & 60 & $4(40)$ & $56(73)$ & ref & ref \\
\hline - $\geq 3 \mathrm{~cm}$ & 27 & $6(60)$ & $21(27)$ & $4.00(1.03-15.6)$ & $0.72(0.11-4.74)$ \\
\hline \multicolumn{6}{|l|}{ Macroscopic type ${ }^{1}$} \\
\hline - Flat & 51 & $3(30)$ & $48(62)$ & ref & \\
\hline - Protruded and mixed & 36 & $7(70)$ & $29(38)$ & $3.86(0.93-16.1)$ & \\
\hline \multicolumn{6}{|l|}{ Tumor depth of invasion } \\
\hline - $\mathrm{pM}$ & 39 & $2(20)$ & $37(48)$ & ref & ref \\
\hline - pSM superficial & 13 & $0(0)$ & $13(17)$ & & \\
\hline - pSM deep & 35 & $8(80)$ & $27(35)$ & $5.48(1.08-27.9)$ & $4.38(0.58-33.2)$ \\
\hline \multicolumn{6}{|l|}{ Histological type } \\
\hline - Differentiated & 64 & $4(40)$ & $60(78)$ & ref & ref \\
\hline - Mixed & 23 & $6(60)$ & $17(22)$ & $5.29(1.34-20.9)$ & $2.25(0.47-10.8)$ \\
\hline \multicolumn{6}{|l|}{ Lymphovascular invasion } \\
\hline - Present & 65 & $4(40)$ & $61(79)$ & ref & ref \\
\hline - Absent & 22 & $6(60)$ & $16(21)$ & $5.72(1.44-22.7)$ & $1.41(0.24-8.26)$ \\
\hline \multicolumn{6}{|l|}{ Tumor location } \\
\hline - EGJ & 70 & $4(40)$ & $66(86)$ & ref & ref \\
\hline - Esophagus & 17 & $6(60)$ & $11(14)$ & $9.0(2.18-37.1)$ & $7.78(1.26-48.1)$ \\
\hline
\end{tabular}

- Table 3 Proportions of lymph node metastasis stratified by tumor depth.

\begin{tabular}{|l|l|l|}
\hline & Number & $95 \% \mathrm{Cl}$ \\
\hline EGJ-BA & & \\
\hline - pM, ly0, v0 & $0 / 34(0 \%)$ & $0-10.2$ \\
\hline - pSM superficial, ly0, v0 & $0 / 10(0 \%)$ & $0-28$ \\
\hline
\end{tabular}

EG], esophagogastric junction; BA, Barrett's adenocarcinoma; Cl, confidence interval; M, intramucosal carcinoma; SM superficial, submucosal invasive cancer $(<500 \mu \mathrm{m})$. ceive appropriate individualized treatment based on both risk of LNM and surgical risks.

The current study has several limitations. First, due to the relatively rare incidence of BA in Japan, the number of cases was small. Our findings should be confirmed in further independent studies. In addition, the number of patients with esophageal$\mathrm{BA}$, in particular, was low compared to those who had EGJ-BA. Length of background Japanese $B E$ is frequently shorter than $10 \mathrm{~mm}$ [37]. Indeed, most of the background BE was maximally shorter than $3 \mathrm{~cm}$ in the current study. Therefore, the number of patients with esophageal-BA was considered to be low. However, we considered tumor location an important risk factor for 
- Table4 Clinicopathological features of lymph node metastasis-positive cases.

\begin{tabular}{|c|c|c|c|c|c|c|c|c|}
\hline No. & Age & Sex & Location & Size $(\mathrm{mm})$ & Macro. & Invasion depth & Histology & LVI \\
\hline 1 & 67 & M & Esophagus & 80 & Is & MM & Diff. & ly $0, v 0$ \\
\hline 2 & 57 & M & EG] & 16 & IIc & MM & Mixed & ly $1, v 1$ \\
\hline 3 & 66 & M & Esophagus & 30 & IIc & SM $1000 \mu \mathrm{m}$ & Mixed & ly $0, v 0$ \\
\hline 4 & 79 & $\mathrm{~F}$ & Esophagus & 60 & IIc & $\mathrm{SM} 1000 \mu \mathrm{m}$ & Diff. & ly 0 , v 0 \\
\hline 5 & 59 & M & EG] & 20 & $|s+1| c$ & SM $1500 \mu \mathrm{m}$ & Diff. & ly $1, v 0$ \\
\hline 6 & 67 & M & EG] & 28 & $\|a+\| c$ & $\mathrm{SM} 2400 \mu \mathrm{m}$ & Mixed & ly 0 , v 0 \\
\hline 7 & 66 & M & Esophagus & 45 & $I s+11 b$ & $\mathrm{SM} 2875 \mu \mathrm{m}$ & Diff. & ly $0, v 1$ \\
\hline 8 & 68 & M & Esophagus & 45 & Ila & SM $3000 \mu \mathrm{m}$ & Mixed & ly $1, v 0$ \\
\hline 9 & 50 & M & EG] & 25 & Is & $\mathrm{SM} 4700 \mu \mathrm{m}$ & Mixed & ly $0, v 1$ \\
\hline 10 & 81 & M & Esophagus & 107 & $|s+1| a$ & $\mathrm{SM} 2350 \mu \mathrm{m}$ & Mixed & ly $1, v 1$ \\
\hline
\end{tabular}

M, male; F, female; Size, tumor size; Macro, macroscopic type; MM, muscularis mucosae; SM, submucosal; Diff., differentiated type adenocarcinoma; Mixed, both differentiated- and undifferentiated-type within one lesion; LVI, lymphovascular invasion; ly, lymphatic invasion; v, vascular invasion.

LNM based on the results with and different wall structures between esophagus and EGJ. Second, pathological evaluation differed between endoscopically and surgically resected specimens. However, the number of pM lesions was very small in surgically resected specimens and it caused selection bias if we used only surgically resected specimens. Therefore, the current study involved both endoscopically and surgically resected specimens. Third, LNM of the endoscopically resected group was judged at 3 years and the follow-up schedule was not decided. Based on the oncological reports, the relapse-free survival curve for patients with pStage I esophageal squamous cell carcinoma decreased within 3 years [38]. Most LNMs after esophagectomy were diagnosed within 2 years based on the surgical series [26]. Therefore, it is considered reasonable to judge LNM at 3 years. Improvement in technology and technique during study periods is another limitation. However, we studied consecutive cases to minimize sampling bias. Therefore patient selection was done independent of technology and technique. Finally, tumor depth of pM could not be analyzed using subclassification of LPM, superficial MM and deep MM due to the small number of patients in the study. Confirmation of the results of the current study by a multicenter validation study is needed.

\section{Conclusions}

The current study demonstrated that tumor location within the esophagus is a potential risk factor for LNM. Therefore, indications for endoscopic treatment of esophageal-BA and EGJ-BA could be different and further studies are needed.

\section{Acknowledgements}

The authors thank Dr. Madhusudhan R. Sanaka (Dept. of Gastroenterology, Cleveland Clinic, Cleveland, $\mathrm{OH}, \mathrm{USA}$ ) for editing this manuscript during his visit to the National Cancer Center Hospital.

\section{Competing interests}

None

\section{References}

[1] Hongo M. Review article: Barrett's oesophagus and carcinoma in Japan. Aliment Pharmacol Ther 2004; 20: (Suppl. 08): 50-54

[2] Brown LM, Devesa SS, Chow WH. Incidence of adenocarcinoma of the esophagus among white Americans by sex, stage, and age. J Natl Cancer Inst 2008; 100: 1184-1187

[3] Yamada M, Kushima R, Oda I et al. Different Histological Status of Gastritis in Superficial Adenocarcinoma of the Esophagogastric Junction. Jpn J Clin Oncol 2013: doi:10.1093/jjco/hyt167

[4] Kusano C, Gotoda T, Khor C] et al. Changing trends in the proportion of adenocarcinoma of the esophagogastric junction in a large tertiary referral center in Japan. J Gastroenterol Hepatol 2008; 23: 1662 1665

[5] Gotoda T, Yanagisawa A, Sasako M et al. Incidence of lymph node metastasis from early gastric cancer: estimation with a large number of cases at two large centers. Gastric Cancer 2000; 3: 219-225

[6] Hirasawa T, Gotoda T, Miyata $S$ et al. Incidence of lymph node metastasis and the feasibility of endoscopic resection for undifferentiatedtype early gastric cancer. Gastric Cancer 2009; 12: 148-152

[7] Pech O, Bollschweiler E, Manner H et al. Comparison between endoscopic and surgical resection of mucosal esophageal adenocarcinoma in Barrett's esophagus at two high-volume centers. Ann Surg 2011; 254: $67-72$

[8] Pech O, May A, Manner $\mathrm{H}$ et al. Long-term efficacy and safety of endoscopic resection for patients with mucosal adenocarcinoma of the esophagus. Gastroenterology 2014; 146: 652 -660, e651

[9] Leers JM, DeMeester SR, Oezcelik A et al. The prevalence of lymph node metastases in patients with T1 esophageal adenocarcinoma a 
retrospective review of esophagectomy specimens. Ann Surg 2011; 253: $271-278$

[10] Nigro J], Hagen JA, DeMeester TR et al. Prevalence and location of nodal metastases in distal esophageal adenocarcinoma confined to the wall: implications for therapy. J Thorac Cardiovasc Surg 1999; 117: $16-23$; discussion 23-15

[11] Rice TW, Blackstone EH, Goldblum JR et al. Superficial adenocarcinoma of the esophagus. J Thorac Cardiovasc Surg 2001; 122: 1077 1090

[12] Stein HJ, Feith M, Bruecher BL et al. Early esophageal cancer: pattern of lymphatic spread and prognostic factors for long-term survival after surgical resection. Ann Surg 2005; 242: 566 - 573; discussion $573-565$

[13] Dunbar KB, Spechler SJ. The risk of lymph-node metastases in patients with high-grade dysplasia or intramucosal carcinoma in Barrett's esophagus: a systematic review. Am J Gastroenterol 2012; 107: 850 862; quiz 863

[14] Siewert SHJR. Adenocarcinoma of the gastroesophageal junction: classification, pathology and extent of resection. Dis Esoph 1996; 9: $173-182$

[15] Amano Y, Ishimura N, Furuta K et al. Which landmark results in a more consistent diagnosis of Barrett's esophagus, the gastric folds or the palisade vessels? Gastrointest Endosc 2006; 64: 206-211

[16] Aida J, Vieth M, Ell C et al. Palisade vessels as a new histologic marker of esophageal origin in ER specimens from columnar-lined esophagus. Am J Surg Pathol 2011; 35: 1140 - 1145

[17] Sharma P, Dent J, Armstrong D et al. The development and validation of an endoscopic grading system for Barrett's esophagus: the Prague C \& M criteria. Gastroenterology 2006; 131: 1392 - 1399

[18] Takizawa K, Matsuda T, Kozu T et al. Lymph node staging in esophageal squamous cell carcinoma: a comparative study of endoscopic ultrasonography versus computed tomography. J Gastroenterol Hepatol 2009; 24: $1687-1691$

[19] Society JE. Japanese Classification of Esophageal Cancer, tenth edition: part II and III. Esophagus 2009; 6: 71 - 94

[20] Society JE. Japanese Classification of Esophageal Cancer, tenth edition: part I. Esophagus 2009; 6: 1-25

[21] Ishihara R, Oyama T, Abe S et al. Risk of metastasis in adenocarcinoma of the esophagus: a multicenter retrospective study in a Japanese population. J Gastroenterol 2016: doi:10.1007/s00535-016-1275-0

[22] Eguchi T, Nakanishi Y, Shimoda T et al. Histopathological criteria for additional treatment after endoscopic mucosal resection for esophageal cancer: analysis of 464 surgically resected cases. Mod Pathol 2006; 19: $475-480$

[23] Oda I, Yamada M, Yoshinaga S et al. Lymph-node metastasis in surgical resection of intramucosal esophageal adenocarcinoma. Dig Endosc 2013; 25: (Suppl. 02): $177-180$

[24] Liu L, Hofstetter WL, Rashid A et al. Significance of the depth of tumor invasion and lymph node metastasis in superficially invasive (T1) esophageal adenocarcinoma. Am J Surg Pathol 2005; 29: 1079-1085
[25] Kaneshiro DK, Post JC, Rybicki L et al. Clinical significance of the duplicated muscularis mucosae in Barrett esophagus-related superficial adenocarcinoma. Am J Surg Pathol 2011; 35: 697-700

[26] Westerterp M, Koppert LB, Buskens C] et al. Outcome of surgical treatment for early adenocarcinoma of the esophagus or gastroesophageal junction. Virchows Arch 2005; 446: 497 - 504

[27] Yajin S, Murakami G, Takeuchi H et al. The normal configuration and interindividual differences in intramural lymphatic vessels of the esophagus. J Thorac Cardiovasc Surg 2009; 137: 1406-1414

[28] Hahn HP, Shahsafaei A, Odze RD. Vascular and lymphatic properties of the superficial and deep lamina propria in Barrett esophagus. Am J Surg Pathol 2008; 32: $1454-1461$

[29] Yamada M, Oda I, Nonaka S et al. Long-term outcome of endoscopic resection of superficial adenocarcinoma of the esophagogastric junction. Endoscopy 2013; 45: $992-996$

[30] Igaki H, Tachimori Y, Kato H. Improved survival for patients with upper and/or middle mediastinal lymph node metastasis of squamous cell carcinoma of the lower thoracic esophagus treated with 3-field dissection. Ann Surg 2004; 239: 483-490

[31] Gillies RS, Simpkin A, Sgromo B et al. Left thoracoabdominal esophagectomy: results from a single specialist center. Dis Esophagus 2011; 24: $138-144$

[32] Oh DS, Hagen JA, Chandrasoma PT et al. Clinical biology and surgical therapy of intramucosal adenocarcinoma of the esophagus. J Am Coll Surg 2006; 203: $152-161$

[33] Manner H, Pech O, Heldmann Y et al. Efficacy, safety, and long-term results of endoscopic treatment for early stage adenocarcinoma of the esophagus with low-risk sm 1 invasion. Clin Gastroenterol Hepatol 2013; 11: 630-635; quiz e645

[34] Manner H, Pech O, Heldmann Y et al. The frequency of lymph node metastasis in early-stage adenocarcinoma of the esophagus with incipient submucosal invasion ( $\mathrm{pT} 1 \mathrm{~b} \mathrm{sm} 1$ ) depending on histological risk patterns. Surg Endosc 2015; 29: 1888-1896

[35] Buskens C], Westerterp M, Lagarde SM et al. Prediction of appropriateness of local endoscopic treatment for high-grade dysplasia and early adenocarcinoma by EUS and histopathologic features. Gastrointest Endosc 2004; 60: $703-710$

[36] Alvarez Herrero L, Pouw RE, van Vilsteren FG et al. Risk of lymph node metastasis associated with deeper invasion by early adenocarcinoma of the esophagus and cardia: study based on endoscopic resection specimens. Endoscopy 2010; 42: 1030-1036

[37] Okita K, Amano Y, Takahashi Y et al. Barrett's esophagus in Japanese patients: its prevalence, form, and elongation. J Gastroenterol 2008; 43: $928-934$

[38] Kato H, Sato A, Fukuda $\mathrm{H}$ et al. A phase II trial of chemoradiotherapy for stage I esophageal squamous cell carcinoma: Japan Clinical Oncology Group Study (JCOG9708). Jpn J Clin Oncol 2009; 39: 638-643 